\title{
Transforming Growth Factor- $\beta 1$ Released from the Spleen Exerts a Growth Inhibitory Effect on Liver Regeneration in Rats
}

\author{
Shuhei Ueda, Akira Yamanoi, Yoshitaka Hishikawa, Dipok Kumar Dhar, \\ Mitsuo Tachibana, and Naofumi Nagasue
}

Department of Digestive and General Surgery (SU, AY, DKD, MT, NN), Shimane Medical University, Izumo, and
Department of Histology and Cell Biology (YH), Nagasaki University School of Medicine, Nagasaki, Japan

SUMMARY: Several previous reports indicated that partial hepatectomy $(\mathrm{PH})$ when combined with splenectomy enhances the regenerative capacity of the liver, most probably due to the removal of unknown inhibitory factors released from the spleen. Transforming growth factor (TGF)- $\beta 1$ is a major antiproliferative factor for the hepatocytes, and the role of splenic TGF- $\beta 1$ in liver regeneration is yet to be clarified. The splenic expression of TGF- $\beta 1$ and its secretion into the portal circulation from the spleen were evaluated in a standardized two-thirds hepatectomy model in rats. Rats in the control group underwent only the hepatectomy, while splenectomy was added in the splenectomy group. The hepatocyte proliferation rate was assessed by proliferating cell nuclear antigen (PCNA) immunostaining, and the results were compared with the TGF- $\beta 1$ kinetics in the portal blood. Significant increase in PCNA index and decrease in portal TGF- $\beta 1$ level were noticed in the splenectomy group at 48 hours after PH compared with the control group. Both TGF- $\beta 1$ protein and mRNA expression level in the spleen were strongest at 48 hours after PH and coincided with the peak of the plasma TGF- $\beta 1$ level. TGF- $\beta$ type II receptor (T $\beta$ R-II) expression in the liver after $\mathrm{PH}$ was assessed immunohistochemically. The expression of $\mathrm{T} \beta \mathrm{R}-\mathrm{Il}$ decreased at 12 hours and returned to preoperative level at 24 hours after PH in both groups. The changes of T $\beta$ R-II expression were similar in both groups, and the significant difference was not observed at 48 hours after PH. Namely, splenectomy did not alter the expression of T $\beta$ R-II in remnant liver at the peak of hepatocytes proliferation. In conclusion we found that TGF- $\beta 1$ was produced and secreted by the spleen during the early phase of liver regeneration and removal of the spleen enhanced proliferation of hepatocytes. Splenectomy thus may exert a salutary effect in selected patients with jeopardized regenerative capacity of the liver. (Lab Invest 2003, 83:1595-1603).

$T$ he liver is the only solid organ in the body that has a tremendous capacity for restoration of tissue loss by regeneration. It has been thought that the liver is continuously undergoing a wear and tear process due to gut-derived factors and regenerates as appropriate (Plauth et al, 1993). Liver regeneration is a highly controlled process and stops once the volume of the lost tissue is restored (Court et al, 2002; Fausto, 2000; Michalopoulos and DeFrances, 1997). Also, the liver is unique in a sense that it is the only organ that receives dual blood supply from two different sources, one of which is portal circulation. It has been assumed that liver functions, including the regenerative capacity, are remotely controlled by the splanchnic organs, including the spleen (Bucher and Swaffield, 1973; Kahn et al, 1990; Starzl et al, 1978).

Transforming growth factor (TGF)- $\beta 1$ is a multifunctional cytokine that works as both proponent or inhibitor of cell proliferation depending on the cell type, differentiation status of the cell, and the milieu in which

DOI: 10.1097/01.LAB.0000095686.10639.C8

Received July 4, 2003.

Address reprint requests to: $D r$. Shuhei Ueda, Department of Digestive and General Surgery, Shimane Medical University, Enya-cho 89-1, Izumo 693-8501, Shimane, Japan. E-mail: shuhei1969@yahoo.co.jp it works (Barnard et al, 1990). TGF- $\beta 1$ is regarded as one of the most potent growth inhibitors for hepatocytes in vitro (Carr et al, 1986; McMahon et al, 1986; Nakamura et al, 1985). The role of TGF- $\beta 1$ in liver regeneration still remains an enigma. Nonetheless, it has been thought that TGF- $\beta 1$ exerts a pivotal role during liver regeneration (Fausto et al, 1991). The liver is housed by different categories of cells of hepatic, biliary, and mesenchymal origin. During liver regeneration all of these cells restore the liver volume through a concerted action in which TGF- $\beta 1$ seems to produce the platform for the newly divided hepatocytes by cementing them to the reconstructed extracellular matrix and thus inhibits further growth of the hepatocytes beyond necessity (Jakowlew et al, 1991; Martinez-Hernandez and Amenta, 1995; Uyama et al, 2002). Simultaneous down-regulation of TGF- $\beta$ type II receptor $(T \beta R-I I)$ by the hepatocytes would make the hepatocytes insensitive to the inhibitory effect of TGF- $\beta 1$ during the proliferative phase. Once the proliferation is completed, the receptors reappear and TGF- $\beta 1$ puts a brake on hepatocyte DNA synthesis (Chari et al, 1995). In addition, activation of latent TGF- $\beta 1$ is necessary for its inhibitory activity. Normal hepatocytes are not able to activate latent TGF- $\beta 1$, but the hepatocytes under regeneration do have such a capability (Jakowlew et al, 1991). Taken together, it 
seems that TGF- $\beta 1$ is a negative regulator of hepatocyte proliferation and in this way restricts the volume of the liver.

To date, several authors have noticed that the removal of the spleen enhances the regenerative capacity of the liver; however, the exact mechanism is yet to be elucidated. It has been mentioned that this is at least partly due to the reduction in portal blood flow following splenectomy (Pérez-Tamayo and Romero, 1958). Therefore, it is theoretically assumed that the spleen produces some inhibitory factors, and ablation of such factors following splenectomy is responsible for the enhanced liver regeneration (Sakai et al, 1977). A protein-like substance in the spleen with a molecular weight of 50,000 to $60,000 \mathrm{Da}$ is an inhibitory factor in liver regeneration (Ohira et al, 1987), but the exact characterization of this factor is yet to be done. Therefore, in this study, we sought to elucidate the kinetics of the TGF- $\beta 1$ expression in the spleen during liver regeneration and also examine the possibility of whether TGF- $\beta 1$ would be released into the portal circulation and would exert its growth inhibitory effect on the hepatocytes following partial hepatectomy in rats.

\section{Results}

\section{Effect of Splenectomy on Hepatic Regeneration and Proliferating Cell Nuclear Antigen (PCNA) Index}

The percentages of PCNA-labeled hepatocytes following partial hepatectomy $(\mathrm{PH})$ with or without splenectomy are shown (Fig. 1). The number of labeled hepatocytes in the control group peaked at 24 hours and decreased gradually with a small secondary peak at 72 hours. On the other hand, in the splenectomy group the number of labeled hepatocytes increased steeply at 24 hours and peaked at 48 hours after $\mathrm{PH}$. Although the number of labeled hepatocytes was higher in the splenectomy group than in the control group from 24 hours to 48 hours time period, it was significant $(11.23 \pm 1.03$ and $3.53 \pm 0.98$, respec-

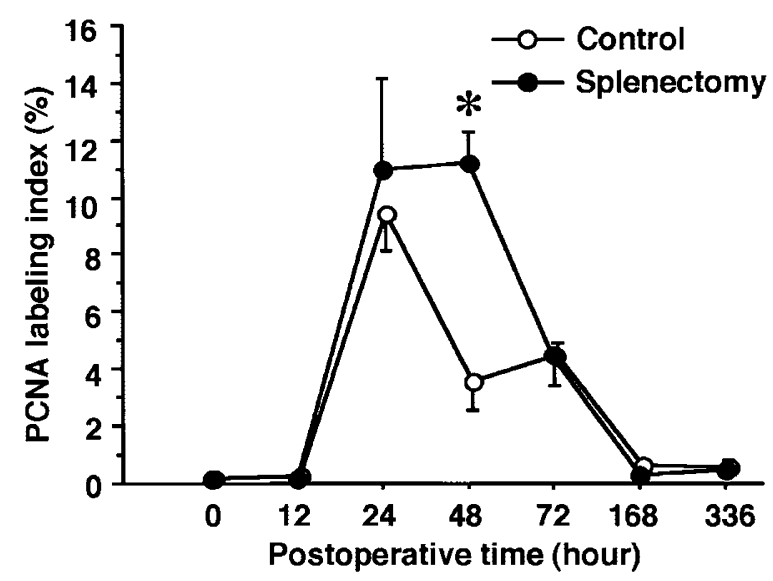

Figure 1.

Percentages of proliferating cell nuclear antigen (PCNA)-labeled hepatocytes following $70 \%$ hepatectomy are shown. Values represent mean \pm SEM $\left({ }^{*} p<0.0003\right)$. At each time point, $n=6$. tively, $p=0.0003$ ) only at the 48-hours time point. The difference between the splenectomy and control group became almost negligible, however, at 72 hours after $\mathrm{PH}$.

\section{Changes in Splenic TGF- $\beta 1$ Expression Following PH}

A quantitative estimation of the splenic TGF- $\beta 1$ was done by Western blot analysis. The anti-TGF- $\beta 1$ antibody detected two distinct bands that were approximately $25 \mathrm{kDa}$ and $12.5 \mathrm{kDa}$ in size, representing the homodimer and monomer of the TGF- $\beta 1$ protein, respectively (Fig. 2A). TGF- $\beta 1$ expression was also noticed in the spleen of sham-treated animals. Densitometric analysis of splenic TGF- $\beta 1$ expression shows that the splenic TGF- $\beta 1$ expression was downregulated at 12 hours after $\mathrm{PH}$, reached the peak value at 48 hours, and then decreased gradually (Fig. 2B). However, there was no significant difference among the various time points.

Next we searched which type of cells in the spleen expressed TGF- $\beta 1$. According to the immunohistochemical analysis, TGF- $\beta 1$ was observed in the splenocytes at all time points (data not shown). Strong expression was observed predominantly in the red pulp, and moderate expression was observed in the white pulp at 48 hours (Fig. 3). Most of the strongly stained cells looked like macrophages and, therefore, a double immunohistochemistry with antibodies against TGF- $\beta 1$ and macrophage was done. Results of this staining indicated that most of the cells taking stain for TGF- $\beta 1$ were of macrophages lineage. Several small round-shaped cells, most likely lymphocytes, were also stained for TGF- $\beta 1$ (Fig. 4). The number of cells expressing TGF- $\beta 1$ increased with the passage of time and peaked at 48 hours following the $\mathrm{PH}$ (data not shown). Thus the immunohistochemical results conformed to those of the Western blot results.

Next it was confirmed whether the TGF- $\beta 1$ transcripts were present in the spleen by in situ hybridization analysis. The positive control kidney tissue had a distinct expression of TGF- $\beta 1$ for the antisense probe and only background intensity for the sense probe (Fig. 5, A and B). A strong TGF- $\beta 1$ mRNA expression was noticed in the red pulp and a weak expression in the white pulp (Fig. 5C) and only background intensity for the sense probe (Fig. 5D). The in situ hybridization results well conformed to those of the immunohistochemical results, indicating that TGF- $\beta 1$ protein was produced from the TGF- $\beta 1$ transcripts in the spleen. Also the highest expression was noticed at the 48hours time point following the $\mathrm{PH}$, which again coincides with the strong expression of TGF- $\beta 1$ protein.

\section{Changes of T及R-Il Expression in the Liver Following PH}

Representative immunohistochemical staining of rat liver for T $\beta \mathrm{R}$-II is shown (Fig. 6). Most expression was observed in hepatocytes, and some expression was also observed in mesenchymal cells. Strong expression was predominantly observed in hepatocytes located along hepatic veins. Analysis of immunohisto- 


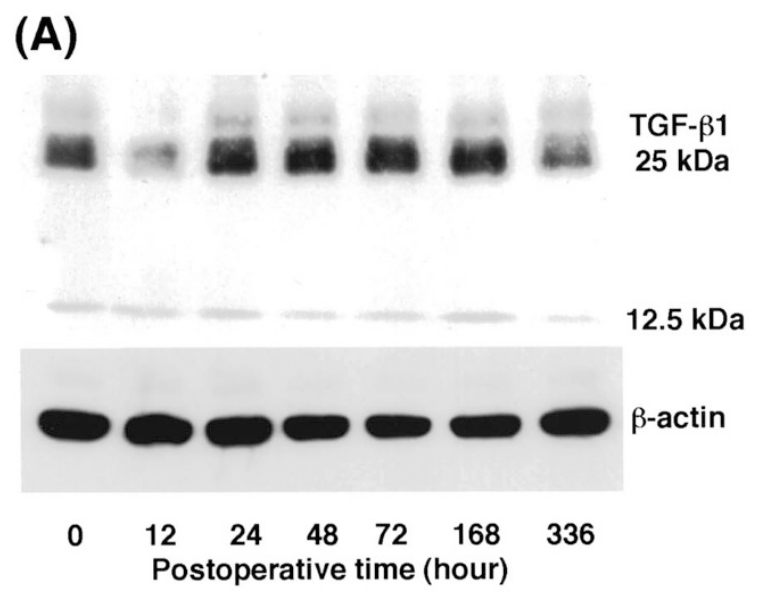

(B)
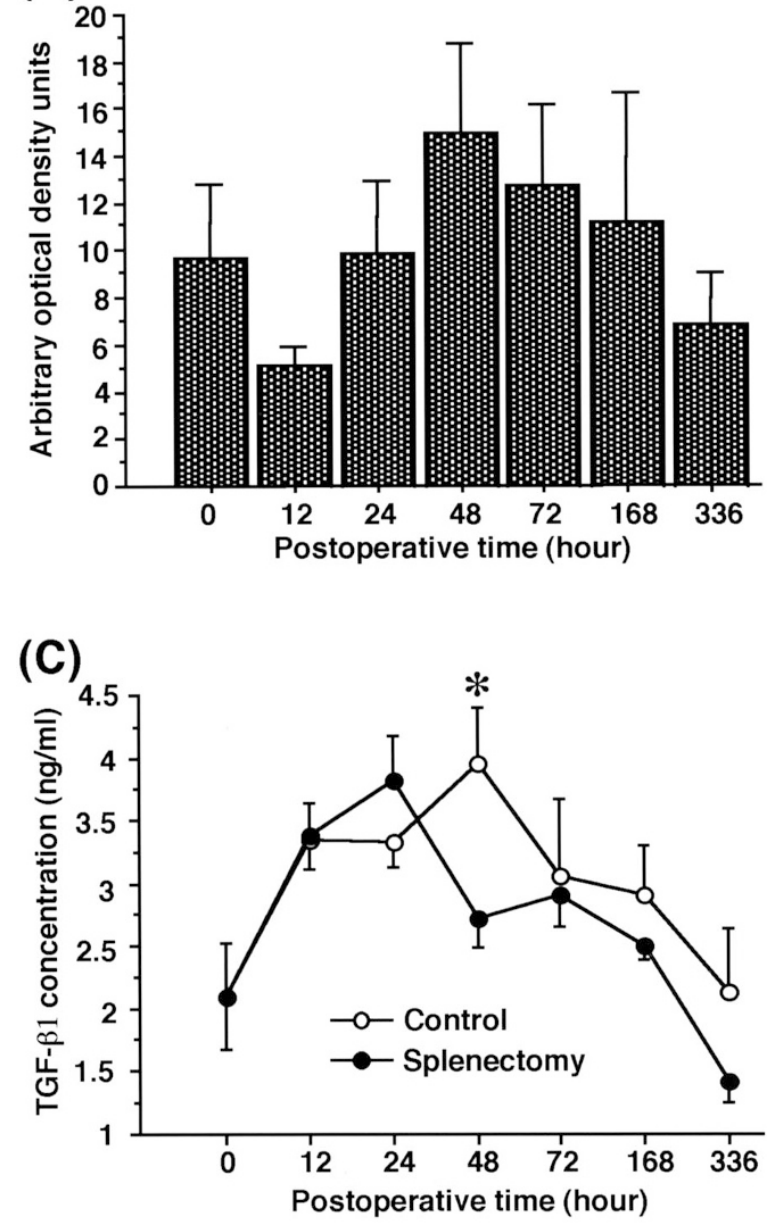

Figure 2.

Changes in splenic transforming growth factor (TGF)- $\beta 1$ expression and plasma TGF- $\beta 1$ in portal vein following $70 \%$ hepatectomy are shown. Expression of splenic TGF- $\beta 1$ ( $25 \mathrm{kDa}$ and $12.5 \mathrm{kDa}$ ) at each time point were analyzed by Western blot analysis using antibody for TGF- $\beta 1$ or $\beta$-actin (60 $\mu \mathrm{g} / \mathrm{lane}$ ). At each time point, $n=6$. (A) Results of one representative experiment are shown. (B) The intensity of each band was calculated with an image analyzer in relation to the $\beta$-actin level. Results represent mean \pm SEM. There is no significant difference among the various points. (C) Plasma TGF- $\beta 1$ (latent and active form) levels in portal vein were measured using ELISA. Results represent mean $\pm \operatorname{SEM}\left({ }^{*} p<0.05\right.$, control group versus splenectomy group at 48 hours after partial hepatectomy).
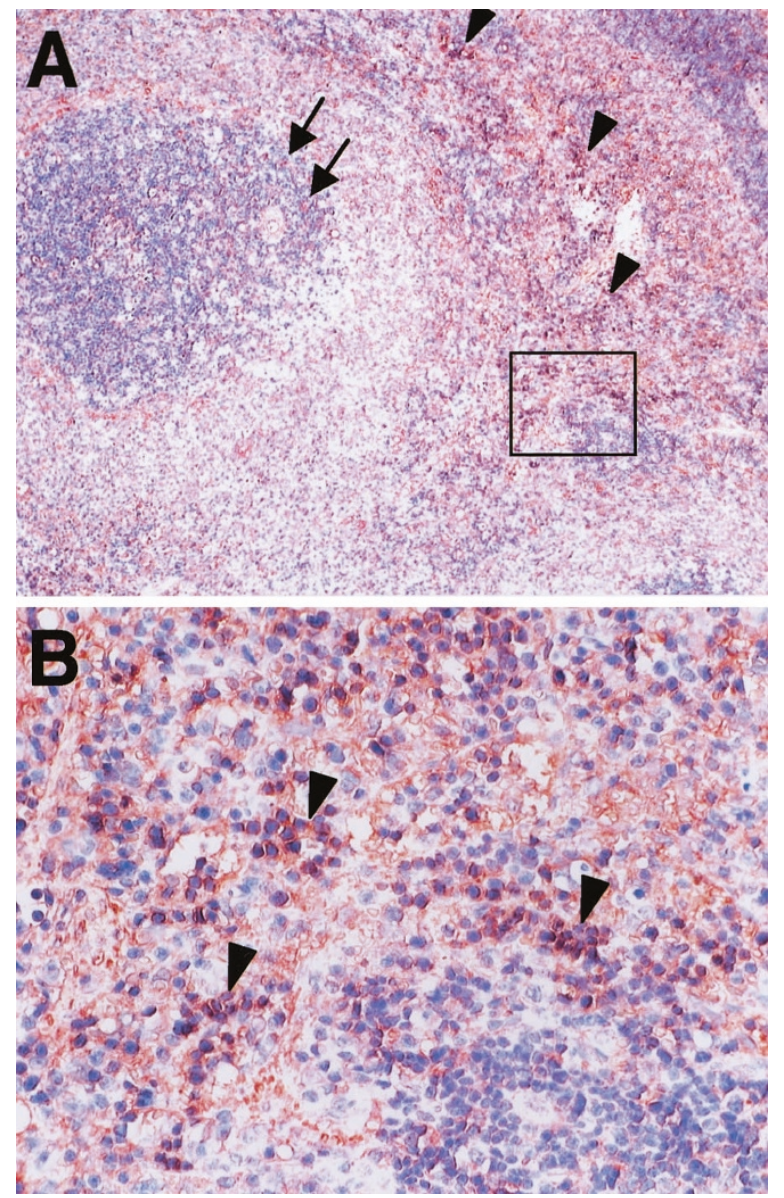

Figure 3.

Immunohistochemistry for transforming growth factor (TGF)- $\beta 1$ in the spleen at 48 hours following $70 \%$ hepatectomy are shown. (A) TGF- $\beta 1$ expression is observed predominantly in the red pulp (arrowheads) and in the white pulp (arrows) a little $(\times 200)$. (B) Macrophage-like cells and small round-shaped cells are stained for TGF- $\beta 1$ in the squared area in $A(\times 400)$.

chemical staining was performed according to the scoring system described in the "Materials and Methods" section. The scores for the T $\beta R$-II expression are shown in Table 1. The expression in the control group decreased 12 hours after $\mathrm{PH}$, recovered until preoperative level at 24-hours time point, and then decreased gradually. At 168 hours the expression was increased again and then decreased a little at 336 hours. The changes of the expression in the splenectomy group were almost the same after $\mathrm{PH}$, and no statistical significance was detected among groups. It was revealed that splenectomy did not alter the T $\beta R$-II expression in the remnant liver after $\mathrm{PH}$ at 48-hours time point.

\section{Changes in Plasma TGF- $\beta 1$ Concentrations in the Portal Vein}

Changes in portal TGF- $\beta 1$ concentrations in relation to the number of PCNA-labeled hepatocytes are shown (Fig. 2C). The values measured in this study were detected as total TGF- $\beta 1$ (latent and active form) because a sample acidification step was included during the assay. In both control and splenectomy 


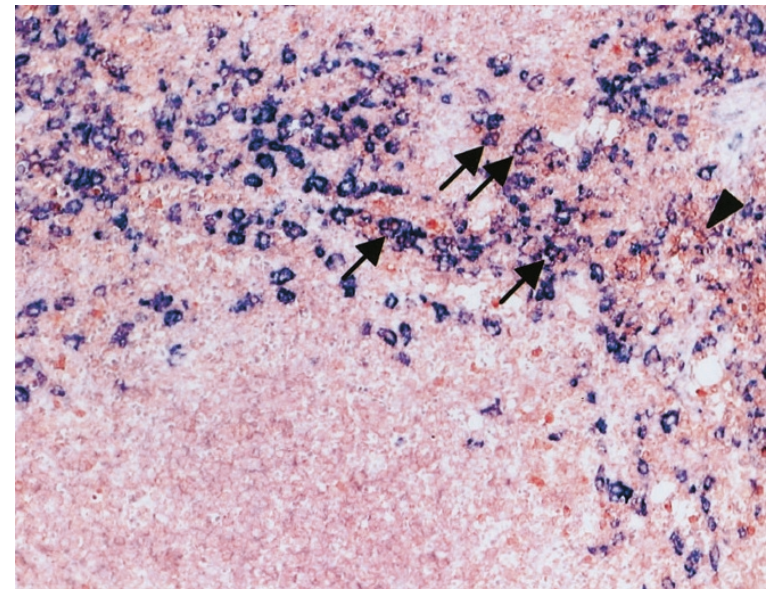

\section{Figure 4.}

Double immunohistochemistry for transforming growth factor (TGF)- $\beta 1$ (red color, cytoplasmic staining) and macrophages (dark purple color, membranous staining) in the spleen 48 hours following $70 \%$ hepatectomy are shown $(\times 200)$. Arrows show doubly stained cells, and an arrowhead shows small round-shaped cells only stained for TGF- $\beta 1$.

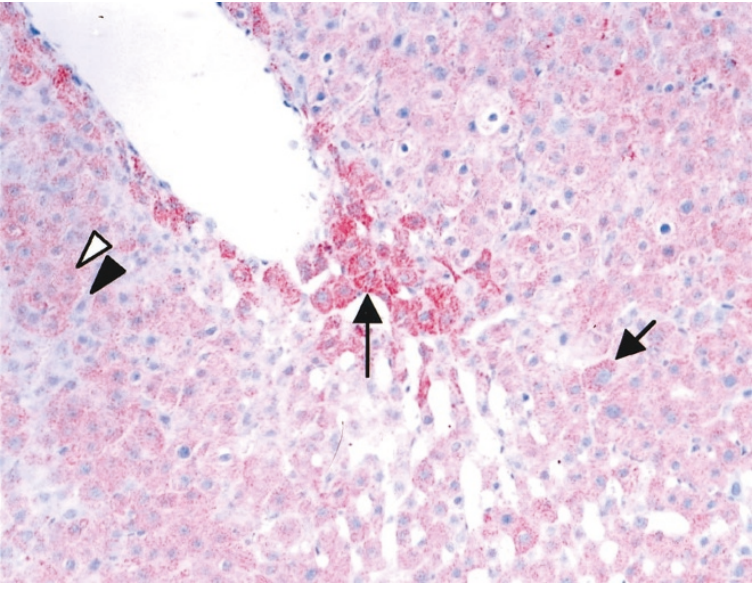

\section{Figure 6.}

Representative immunohistochemistry for transforming growth factor (TGF)- $\beta$ type II receptor $(T \beta R-I I)$ in the liver is shown $(\times 400)$. A closed arrowhead shows negative staining, an open arrowhead shows weakly positive staining, a short arrow shows moderately positive staining, and a long arrow shows strongly positive staining of representative hepatocytes, respectively. Scores for T $\beta$ R-II staining are determined as described in "Materials and Methods" section.
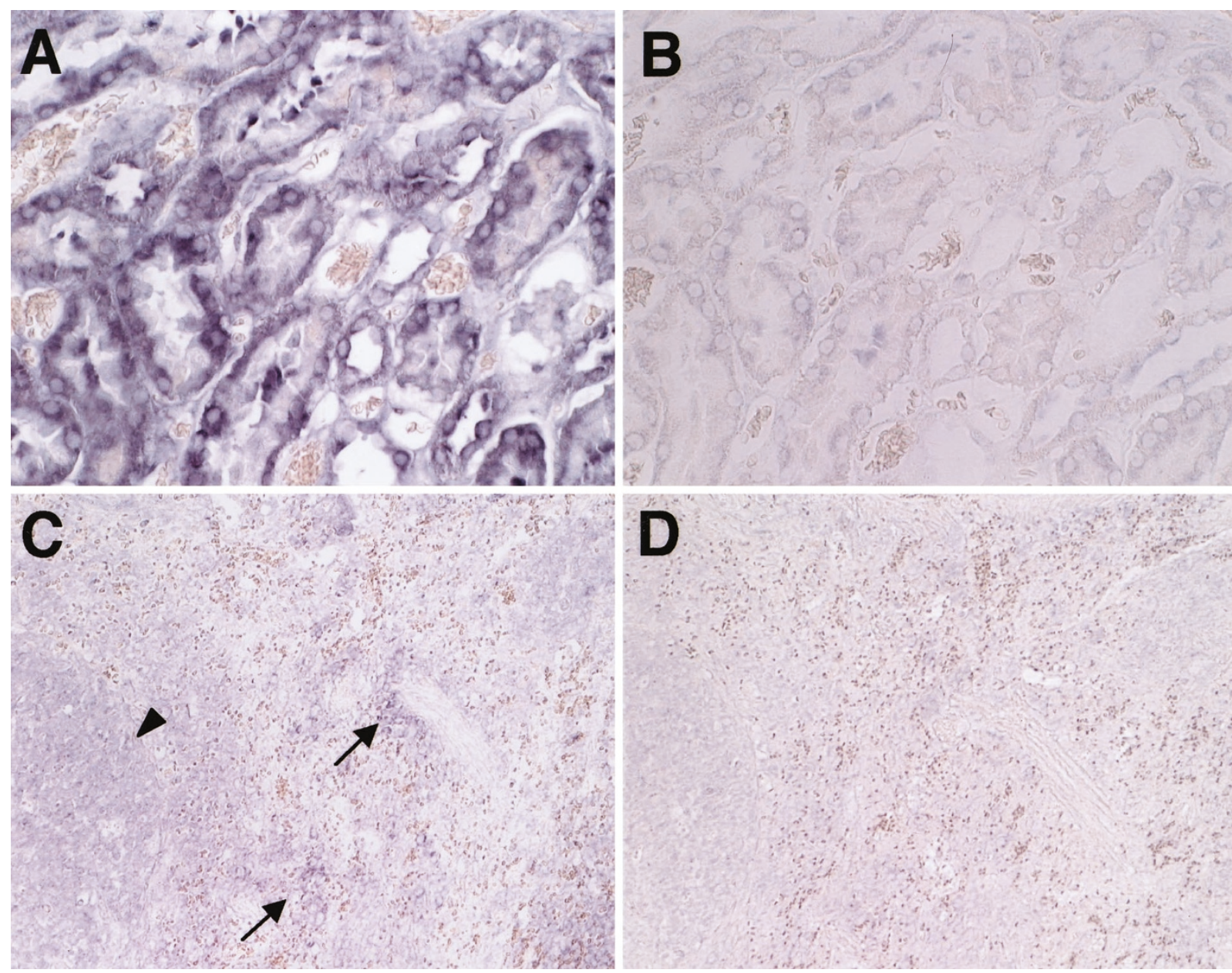

\section{Figure 5.}

In situ hybridization using transforming growth factor (TGF)- $\beta 1$ riboprobe on the spleen at 48 hours following $70 \%$ hepatectomy are shown $(\times 200)$. Kidney sections are used as control (A, antisense probe; B, sense probe). (C) TGF- $\beta 1$ mRNA expression is noticed in the red pulp (arrows), and a weak expression in the white pulp (arrowhead) using antisense probe. (D) Only background intensity is recognized using sense probe. 
groups, plasma TGF- $\beta 1$ concentrations increased after $\mathrm{PH}$ and returned to the baseline at 336 hours. The peak time point was at 48 hours in the control group and 24 hours in the splenectomy group. At 48 hours plasma TGF- $\beta 1$ concentration was significantly higher in the control group (mean \pm SEM, $3.97 \pm 0.44 \mathrm{ng} / \mathrm{ml}$ ) than in the splenectomy group (mean \pm SEM, $2.73 \pm$ $0.24 \mathrm{ng} / \mathrm{ml})(p<0.05)$.

\section{Discussion}

The origin of TGF- $\beta 1$ during liver regeneration has been much debated. Earlier studies have mentioned that the mesenchymal cells, including the endothelial cells in the liver, are the major source of TGF- $\beta 1$ and that this inhibitory growth factor works on the hepatocytes in a paracrine manner (Braun et al, 1988; Fausto and Mead, 1989; Fausto et al, 1995; Jakowlew et al, 1991; Nakatsukasa et al, 1990). However, later studies showed that the hepatocytes themselves also produce TGF- $\beta 1$ and exert the growth inhibitory effect in an autocrine manner (Bissell et al, 1995; Schrum et al, 2001). In addition to a paracrine or autocrine manner, TGF- $\beta 1$ may have a growth inhibitory effect on the hepatocytes in an endocrine manner (Russell et al, 1988). In this study, we report that the splanchnic organs including the spleen might be another vital source of TGF- $\beta 1$ that works as an endocrine factor by exerting the growth inhibitory effect on liver regeneration. Formation of latent complexes may switch endogenous TGF- $\beta 1$ from an autocrine/paracrine mode of action to a more endocrine mode involving target organs distant from the site of synthesis (Wakefield et al, 1990). Human TGF- $\beta 1$ may have endocrine roles, while TGF- $\beta 2$ and TGF- $\beta 3$ appear to act only in a local autocrine/paracrine fashion (Wakefield et al, 1995). TGF- $\beta 1$ is now known to act via autocrine, paracrine, and endocrine modes to control a wide variety of developmental processes (Roberts, 1998). TGF- $\beta 1$ is secreted from the producer cells as latent complexes of high molecular weights with help from the latent TGF- $\beta 1$ binding protein (Miyazono et al, 1991). Because TGF- $\beta 1$ is a ubiquitous molecule, the activation of the latent complex is likely to be an important step in the action of this factor (Lyons and Moses, 1990; Pircher et al, 1984; Wakefield et al, 1987). To the best of our knowledge, this is the first report describing the changes in TGF- $\beta 1$ level in the portal blood flow and in the spleen following $\mathrm{PH}$ in rats. However, in the present study, whether the TGF- $\beta 1$ measured in the portal vein was the latent form or active form could not be distinguished because the ELISA kit used in this study needed a complete acidification step. Thus which form of the TGF- $\beta 1$ dominant in the portal vein and which form influenced the liver regeneration are not known.

Serial changes in the production of splenic TGF- $\beta 1$ and in the plasma TGF- $\beta 1$ in the portal blood related to liver regeneration after $\mathrm{PH}$ were measured for the first time in this report. It was reported that simultaneous splenectomy with $\mathrm{PH}$ accelerated liver regen- eration, but at the end of 28 days, the amount of the regenerated liver was the same as that in the nonsplenectomized, partially hepatectomized controls (Higgins and Priestley, 1932). This effect was not due to the decrease in blood volume produced by splenectomy nor to modifications in the portal blood flow. Because the effect was recognized regardless of the volume or the position of spleen, it was concluded that a humoral factor or factors may be involved (PérezTamayo and Romero, 1958). More recently, several studies showed that the spleen contained an unrecognized hepatocyte growth inhibitory factor (Ohira et al, 1987; Sakai et al, 1977; Sen Gupta et al, 1968). Results of our study furthered the results of the previous studies that TGF- $\beta 1$ produced in the spleen serves as a hepatocyte growth inhibitory factor.

Results of this study conceivably showed that TGF- $\beta 1$ was increasingly synthesized in the spleen and was secreted into the portal blood stream following $\mathrm{PH}$. The peak of splenic TGF- $\beta 1$ expression and that of plasma TGF- $\beta 1$ concentration coincided in time, that being at 48 hours after $\mathrm{PH}$. Concomitant decrease in the number of PCNAlabeled hepatocytes may indicate that TGF- $\beta 1$ produced by the spleen may have some inhibitory effect on hepatocyte proliferation. Indeed, removal of the spleen significantly increased the number of proliferating cells at 48 hours after $\mathrm{PH}$ compared with the control rats, thus indicating that spleenoriginated TGF- $\beta 1$ produced an inhibitory effect on hepatocyte proliferation. A limitation of our study is that measurement of TGF- $\beta 1$ level in the portal vein did not reflect solely the spleen-derived TGF- $\beta 1$ because the portal flow may contain substances from the pancreas, stomach, and intestine. It is worth mentioning that the splenectomy operation did not abolish the increase in the portal TGF- $\beta 1$ level following $\mathrm{PH}$. This may simply indicate that other organs than the spleen such as the intestine, pancreas, or stomach may be another source of TGF- $\beta 1$ in portal circulation. TGF- $\beta 1$ released from these organs may have a similar antiproliferative effect on hepatocytes. Indeed, it was shown that ileocolectomy with $50 \% \mathrm{PH}$ resulted in a significantly greater regenerative response on the 3rd day than hepatectomy alone or hepatectomy plus partial ileal resection in pigs (Kahn et al, 1990). They concluded that the proximal colon might be the source of a hepatic regeneration inhibitory factor. Our results indicate that this inhibitory factor could be TGF- $\beta 1$; however, further studies are necessary before reaching a firm conclusion. Both the double immunohistochemistry and in situ hybridization results confirmed the localization of TGF- $\beta 1$ in the macrophages of the spleen. While our work was in progress, a similar increase in the production of TGF- $\beta 1$ by the splenic macrophages in a cirrhotic model of rats was reported and a conclusion was made that TGF- $\beta 1$ was released into the portal circulation (Akahoshi et al, 2002). They also concluded that splenic TGF- $\beta 1$ produced growth inhibitory effect on the cirrhotic liver, and we concur with 
them that a similar mechanism may have taken place during liver regeneration following $\mathrm{PH}$. Similarly, it was shown that Sho-saiko-to extract (glycyrrhetic acid, baicalin, and baicalein) caused enhanced liver regeneration by inhibiting the production of TGF- $\beta 1$ in the spleen in $70 \%$ partially hepatectomized rats with dimethylnitosamineinduced liver-injury model (Ono et al, 2000). This further proves our hypothesis that the spleen contributes a major inhibitory role in liver regeneration by producing and releasing TGF- $\beta 1$.

The expression of $\mathrm{T} \beta \mathrm{R}-\mathrm{Il}$ in the remnant liver after $\mathrm{PH}$ is still controversial. After $\mathrm{PH}$, all of the TGF- $\beta$ receptors of the liver decreased at the mRNA and protein level, and only the type II receptor recovered within 96 hours after $\mathrm{PH}$. The return of the receptor expression may be involved in limiting hepatocyte proliferation with insensitivity to TGF- $\beta$ (Chari et al, 1995). The peak of hepatocyte sensitivity to TGF$\beta 1$-mediated growth inhibition was 2 days after $\mathrm{PH}$, and the peak of T $\beta$ R-II expression was 4 days after $\mathrm{PH}$ (Nishikawa et al, 1998). Our study revealed that $\mathrm{T} \beta \mathrm{R}$-II expression was decreased 12 hours after $\mathrm{PH}$, with recovery at the 24-hours time point; splenectomy did not affect the expression at the 48-hours time point. Liver cell proliferation is a highly controlled process, and a concerted involvement of several growth proponent and inhibitory factors is postulated. It was reported that resting hepatocytes were more sensitive than regenerating hepatocytes, and the difference was remarkable under norepinephrine treatment condition (Houck and Michalopoulos, 1989). Thus the sensitivity of hepatocytes to TGF- $\beta 1$ depends on several factors, including the experimental conditions (in vivo or in vitro). Also there is a great possibility that in addition to TGF- $\beta$, other factors that have significant growth inhibitory effect on hepatocytes, such as activin (Yasuda et al, 1993), IL (IL)-1 (Boulton et al, 1997), norepinephrine (Houck and Michalopoulos, 1989), or hypoxic condition (Kakihara et al, 2000) are also involved in this process.

In conclusion, we found that TGF- $\beta 1$ was produced and secreted by the spleen during the early phase of liver regeneration. It might be possible that TGF- $\beta 1$ released from the spleen worked as a humoral inhibitory factor for hepatocyte proliferation and thus removal of spleen enhance liver regeneration during the early regenerative phase following $\mathrm{PH}$. The spleen harbors a large number of cells of the immune system and modulates the biological function in several ways, including secretion of endothelin in noncirrhotic portal hypertension (Nagasue et al, 2000). Experimental studies and clinical findings show that splenectomy may salvage the cirrhotic liver or reduce the portal hypertension (Nagasue et al, 1999). Splenectomy may exert a similar salutary effect in selected patients with jeopardized regenerative capacity of the liver; however, further studies are needed to clarify the exact mechanism for the increased synthesis of TGF- $\beta 1$ in the spleen during liver regeneration.

\section{Materials and Methods}

\section{Animals}

Male Sprague-Dawley rats of 7 to 8 weeks of age (180 to $250 \mathrm{~g}$ body weight) were obtained from the Charles River Breeding Laboratories, Kanagawa, Japan. All animals were kept under constant temperature and a 12-hour dark/light cycle. Food (standard laboratory chow) and water were allowed ad libitum. The animals were handled according to the guidelines established by the Animal Research Center of Shimane Medical University.

\section{Experimental Design}

$\mathrm{PH}$ consisted of resection of the left lateral and median lobes ( $70 \%$ of the liver), according to Higgins and Anderson (1931). All surgeries were performed under light diethylether anesthesia at room temperature between 9:00 am and 12:00 noon, and the animals were maintained postoperatively on food and water ad libitum. Twelve animals were assigned to each of the six time points $(12,24,48,72,168$, and 336 hours after surgery), with six rats having partial hepatectomy only (control group); another six rats underwent the hepatectomy and splenectomy operation (splenectomy group). Another six rats were killed after manipulation of the liver lobes to collect the baseline data at 0-hour time point (sham operated group). Portal venous blood was collected into tubes containing $20 \mathrm{~mm}$ EDTA (final concentration) before animal sacrifice and centrifuged at $3000 \times g$ for 5 minutes to collect plasma. Plasma samples were stored at $-80^{\circ} \mathrm{C}$ for subsequent use. The liver and spleen were rapidly removed by standard dissection techniques, and a portion was minced and immediately frozen in liquid nitrogen to prepare total protein for immunoblot analysis. Another portion was fixed in chilled $4 \%$ paraformaldehyde or absolute methanol and then embedded in paraffin for immunohistochemistry and in situ hybridization.

\section{Immunohistochemistry}

Liver tissues fixed with absolute methanol were used for PCNA analysis (Mancini et al, 1994; Suzuki et al, 1992). Spleen and liver tissues fixed with $4 \%$ paraformaldehyde were used for TGF- $\beta 1$ analysis and T $\beta$ R-II analysis, respectively. Immunohistochemical study was performed using the streptavidin-biotin method with a Histofine SAB-PO(M) Kit (Nichirei, Tokyo, Japan) for PCNA and TGF- $\beta 1$ analysis, and a Histofine $\mathrm{SAB}-\mathrm{PO}(\mathrm{R})$ Kit (Nichirei, Tokyo, Japan) for $\mathrm{T} \beta \mathrm{R}-\mathrm{II}$ analysis. The optimal dilutions of primary antibodies were as follows: TGF- $\beta 1$ (clone TB21, Serotec Ltd., Oxford, England; 1:500 dilution), PCNA (clone PC10, DAKO A/S, Glostrup, Denmark; 1:100 dilution), and T $\beta$ R-II (clone C-16, Santa Cruz Biotechnology, Inc., Santa Cruz, California; 1:100 dilution). Endogenous peroxidase activity was blocked by incubating the slides with $3 \%$ hydrogen peroxide for 15 minutes. Then the sections were incubated for 15 minutes with 
normal serum from the same donor species in which the secondary antibodies were developed. Excess of the blocking serum was removed and followed by an overnight incubation with the primary antibodies. Link antibodies were applied for 15 minutes. The sections were incubated for 15 minutes with streptavidinperoxidase solution. Between steps, slides were washed with PBS solution. Color was developed with 3-amino-9-ethylcarbazole, and counterstaining was with Mayer's hematoxylin. Double immunohistochemistry was also performed for TGF- $\beta 1$ and macrophages in the spleen tissues. The primary antibody for macrophages (ED2, BMA Biomedicals AG, Augst, Switzerland; 1:50 dilution) reacts with rat resident macrophages. The procedure of double immunohistochemistry involves the technique of two 5-minute microwave oven heatings (Lan et al, 1995). The procedure was performed with a slight modification as follows. The first round of staining for macrophages was done using the streptavidin-biotin method with a DAKO LSAB 2 Kit, AP, Rat (DAKO Corporation, Carpinteria, California) according to the kit instruction manual, and color was developed with NBT/BCIP Stock Solution (Roche Diagnostics, GmbH, Mannheim, Germany) according to the company's instruction manual. After the first round of staining, crossreactivity between sequential rounds of staining was blocked by two 5-minute microwave oven heatings of slides in citrate buffer ( $\mathrm{pH}$ 6.0). The second round of staining for TGF- $\beta 1$ was done as described above, but counterstaining was not made.

\section{Calculation of PCNA Labeling Index}

The PCNA labeling index corresponds to the ratio between the positive nuclei and the total hepatocyte nuclei population in a defined area. Ten fields with highest densities of stained cells were selected at random at low magnification $(\times 100)$, and then the number of positive nuclei was counted at high power magnification $(\times 400)$. Usually nuclei from 800 to 1000 hepatocytes were counted blindly by two independent observers in each case, and the mean value was regarded as the number of PCNA positive cells.

\section{Evaluation of T及R-Il Staining}

$\mathrm{T} \beta \mathrm{R}-\mathrm{Il}$ expression on hepatocytes excluding mesenchymal cells in all stained specimens was evaluated according to a scoring system of staining as described previously (Koga et al, 1999). In brief, the intensity of staining for $\mathrm{T} \beta \mathrm{R}$-II was scored in each specimen on a scale of 0 to 3 , in which $0=$ negative staining, $1=$ weakly positive staining, 2 = moderately positive staining, and 3 = strongly positive staining. The intensity of staining was evaluated for the maximum intensity among positive cells ("maximum intensity of staining") and the intensity level observed in the largest number of positive cells ("most extensive intensity level"). The extent to which positive cells were seen in each specimen ("extent of distribution" of positive cells) was estimated and scored on a scale of 0 to 4 , in which $0=$ negative; $1=$ positive staining in $1 \%$ to $25 \%$ of cells; 2 , in $26 \%$ to $50 \%$; 3 , in $51 \%$ to $75 \%$; and 4 , in $76 \%$ to $100 \%$. Each section was evaluated for the sum of these three parameters.

\section{Western Blot Analysis}

Spleen tissues collected at each time point were homogenized in ice-cold buffer containing $0.1 \%$ TritonX-100, 0.4 M NaCl, 20 mm Tris-HCl, 1 mm EDTA, $1 \mathrm{~mm}$ PMSF, $1 \mathrm{mg} / \mathrm{ml}$ aprotinin, $1 \mathrm{mg} / \mathrm{ml}$ leupeptin, 1 $\mathrm{mg} / \mathrm{ml}$ pepstatin $\mathrm{A}$, and $2.5 \mathrm{mg} / \mathrm{ml}$ sodium deoxycholate. Samples were centrifuged at $10,000 \times g$ for 5 minutes, and protein concentration of supernatants was measured spectrophotometrically at A595 with Protein Assay CBB Solution (5X) (Nacalai Tesque, Kyoto, Japan). Aliquots containing $60 \mu \mathrm{g}$ of protein were resolved on $15 \%$ SDS-PAGE gels. The protein bands of gels were transferred onto Immun-Blot PVDF membrane for protein blotting $(0.2 \mu \mathrm{m})$ (Bio-Rad Laboratories, Hercules, California). Gels were stained with Coomassie blue after completion of the transfer to Immun-Blot PVDF membrane to prove equal protein loads. The membranes were incubated with antiTGF- $\beta 1$ antibody (same antibody used for immunohistochemistry, 1:1000 dilution) and then horseradish peroxidase-linked goat antimouse lgG antibody (MBL, Nagoya, Japan; 1:2000 dilution). The antigen-antibody reactions were visualized using ECL Western blotting detection reagents (Amersham Pharmacia Biotech, Buckinghamshire, England) followed by exposure of the membranes to Kodak medical X-ray film (Eastman Kodak Company, Rochester, New York). The reacted membranes were stripped off and reprobed with anti$\beta$-actin antibody (Sigma-Aldrich, St. Louis, Missouri) as protein load control. Blots were scanned with a scanner ES-2000 (Epson, Tokyo, Japan) and analyzed with NIH Image 1.61 software. All experimental results were normalized to the densities of $\beta$-actin.

\section{Determination of Plasma TGF- $\beta 1$}

Plasma TGF- $\beta 1$ (ng/ml) content was measured by an ELISA kit (Genzyme, Cambridge, Massachusetts) as described previously (Morii et al, 1999). EDTA-treated samples were centrifuged once at $10,000 \times g$ for 10 minutes at $4^{\circ} \mathrm{C}$ to completely remove the platelets as instructed by the manufacturer of the kit. Assays were performed in duplicate.

\section{In Situ Hybridization}

Representative sections from harvested spleens from each time point were used for in situ hybridization. Parallel sections were used for sense and antisense probe. A 389-bp length of cDNA of the TGF- $\beta 1$ gene (gene bank accession number NM-000660, from position 1171 to 1560 ) having homology with rat TGF- $\beta 1$ was amplified by nested PCR and cloned into a TA cloning vector (pGEM-T Easy Vector Systems, Promega, Madison, Wisconsin). The sequence of the insert was confirmed with a DNA sequencer (Applied Biosystems, Norwalk, Connecticut) at the SAWADY 
Technology Ltd., Tokyo, Japan. A digoxigenin-labeled sense and antisense RNA probe was transcribed by T7 and SP6 RNA polymerase, respectively, with a DIG RNA labeling kit according to the manufacturer's instructions (Boehringer Mannheim, Mannheim, Germany). Hybridization and the immunohistochemical steps were done as we described previously (Nagasue et al, 2000). Rat kidney tissue section was used as a positive control.

\section{Statistical Analysis}

In all analyses involving comparisons among the groups, statistical significance was determined using the Bonferroni Dunn procedure, with the significance level set at 5\%. Analyses were performed using Stat View version 5.0 software (Abacus Concepts, Berkeley, California). All data are expressed as mean \pm SEM.

\section{References}

Akahoshi T, Hashizume M, Tanoue K, Shimabukuro R, Gotoh N, Tomikawa M, and Sugimachi K (2002). Role of the spleen in liver fibrosis in rats may be mediated by transforming growth factor beta-1. J Gastroenterol Hepatol 17:59-65.

Barnard JA, Lyons RM, and Moses HL (1990). The cell biology of transforming growth factor beta. Biochim Biophys Acta 1032:79-87.

Bissell DM, Wang SS, Jarnagin WR, and Roll FJ (1995). Cell-specific expression of transforming growth factor- $\beta$ in rat liver. J Clin Invest 96:447-455.

Boulton R, Woodman A, Calnan D, Selden C, Tam F, and Hodgson $H$ (1997). Nonparenchymal cells from regenerating rat liver generate interleukin-1alpha and -1beta: A mechanism of negative regulation of hepatocyte proliferation. Hepatology 26:49-58.

Braun L, Mead JE, Panzica M, Mikumo R, Bell GI, and Fausto $N$ (1988). Transforming growth factor $\beta$ mRNA increases during liver regeneration: A possible paracrine mechanism of growth regulation. Proc Natl Acad Sci USA 85:1539-1543.

Bucher NL and Swaffield MN (1973). Regeneration of liver in rats in the absence of portal splanchnic organs and a portal blood supply. Cancer Res 33:3189-3194.

Carr BI, Hayashi I, Branum EL, and Moses HL (1986). Inhibition of DNA synthesis in rat hepatocytes by plateletderived type $\beta$ transforming growth factor. Cancer Res 46:2330-2334.

Chari RS, Price DT, Sue SR, Meyers WC, and Jirtle RL (1995). Down-regulation of transforming growth factor beta receptor type I, II, and III during liver regeneration. Am J Surg 169: 126-131; discussion 131-132.

Court FG, Wemyss-Holden SA, Dennison AR, and Maddern GJ (2002). The mystery of liver regeneration. Br J Surg 89:1089-1095.

Fausto N (2000). Liver regeneration. J Hepatol 32(Suppl 1):19-31.

Fausto N and Mead JE (1989). Regulation of liver growth: Proto-oncogenes and transforming growth factors. Lab Invest 60:4-13.
Fausto N, Laird AD, and Webber EM (1995). Liver regeneration. 2. Role of growth factors and cytokines in hepatic regeneration. FASEB J 9:1527-1536.

Fausto N, Mead JE, Gruppuso PA, Castilla A, and Jakowlew SB (1991). Effects of TGF-beta $s$ in the liver: Cell proliferation and fibrogenesis. Ciba Found Symp 157:165-174; discussion 174-177.

Higgins GM and Anderson RM (1931). Experimental pathology of the liver: I. Restoration of the liver of the white rat following partial surgical removal. Arch Pathol 12:186-202.

Higgins GM and Priestley JT (1932). Experimental pathology of the liver: VI. Restoration of the liver in white rats after partial removal and splenectomy. Arch Pathol 13:573-583.

Houck KA and Michalopoulos GK (1989). Altered responses of regenerating hepatocytes to norepinephrine and transforming growth factor type beta. J Cell Physiol 141:503-509.

Jakowlew SB, Mead JE, Danielpour D, Wu J, Roberts AB, and Fausto $N$ (1991). Transforming growth factor-beta (TGFbeta) isoforms in rat liver regeneration: Messenger RNA expression and activation of latent TGF-beta. Cell Regul 2:535-548.

Kahn D, Von Sommoggy S, Hickman R, and Terblanche J (1990). Ileocolectomy enhances the regenerative response after partial hepatectomy in the pig. S Afr J Surg 28:11-13.

Kakihara N, Takeshita K, Ishibashi H, Tani T, and Kodama M (2000). Hypoxic conditions restore lost sensitivity to the growth inhibitory effect of transforming growth factor beta-1 (TGF beta-1) in proliferating rat hepatocytes in vitro. Life Sci 67:2929-2940.

Koga H, Sakisaka S, Ohishi M, Kawaguchi T, Taniguchi E, Sasatomi K, Harada M, Kusaba T, Tanaka M, Kimura R, Nakashima Y, Nakashima O, Kojiro M, Kurohiji T, and Sata M (1999). Expression of cyclooxygenase-2 in human hepatocellular carcinoma: Relevance to tumor dedifferentiation. Hepatology 29:688-696.

Lan HY, Mu W, Nikolic-Paterson DJ, and Atkins RC (1995). A novel, simple, reliable, and sensitive method for multiple immunoenzyme staining: Use of microwave oven heating to block antibody crossreactivity and retrieve antigens. J Histochem Cytochem 43:97-102.

Lyons RM and Moses HL (1990). Transforming growth factors and the regulation of cell proliferation. Eur $\mathrm{J}$ Biochem 187:467-473.

Mancini R, Marucci L, Benedetti A, Jezequel AM, and Orlandi F (1994). Immunohistochemical analysis of S-phase cells in normal human and rat liver by PC10 monoclonal antibody. Liver 14:57-64.

Martinez-Hernandez A and Amenta PS (1995). The extracellular matrix in hepatic regeneration. FASEB J 9:1401-1410.

McMahon JB, Richards WL, del Campo AA, Song MK, and Thorgeirsson SS (1986). Differential effects of transforming growth factor-beta on proliferation of normal and malignant rat liver epithelial cells in culture. Cancer Res 46:4665-4671.

Michalopoulos GK and DeFrances MC (1997). Liver regeneration. Science 276:60-66.

Miyazono K, Olofsson A, Colosetti P, and Heldin CH (1991). A role of the latent TGF-beta 1-binding protein in the assembly and secretion of TGF-beta 1. EMBO J 10:1091-1101.

Morii Y, Kawano K, Hiratsuka K, Inomata M, Yoshida T, and Kitano S (1999). Inhibition by endotoxemia of rat liver regen- 
eration following partial hepatectomy with special reference to cytokine production. Hepatol Res 13:120-132.

Nagasue N, Dhar DK, Yamanoi A, Emi Y, Udagawa J, Yamamoto A, Tachibana M, Kubota H, Kohno H, and Harada $T$ (2000). Production and release of endothelin-1 from the gut and spleen in portal hypertension due to cirrhosis. Hepatology 31:1107-1114.

Nagasue N, Kohno H, Yamanoi A, Ohmori H, Dhar DK, Makino Y, Kimoto T, and Tachibana M (1999). Role of splenectomy in hepatic resection for hepatocellular carcinoma associated with severe cirrhosis and hypersplenism. Hepatol Res 14:35-48.

Nakamura T, Tomita Y, Hirai R, Yamaoka K, Kaji K, and Ichihara A (1985). Inhibitory effect of transforming growth factor-beta on DNA synthesis of adult rat hepatocytes in primary culture. Biochem Biophys Res Commun 133:10421050.

Nakatsukasa H, Evarts RP, Hsia CC, and Thorgeirsson SS (1990). Transforming growth factor-beta 1 and type I procollagen transcripts during regeneration and early fibrosis of rat liver. Lab Invest 63:171-180.

Nishikawa Y, Wang M, and Carr BI (1998). Changes in TGF-beta receptors of rat hepatocytes during primary culture and liver regeneration: Increased expression of TGF-beta receptors associated with increased sensitivity to TGF-beta-mediated growth inhibition. J Cell Physiol 176:612-623.

Ohira M, Umeyama K, Taniura M, Yamashita T, and Morisawa $S$ (1987). An experimental study of a splenic inhibitory factor influencing hepatic regeneration. Surg Gynecol Obstet 164:438-444.

Ono M, Miyamura M, Kyotani S, Saibara T, Ohnishi S, and Nishioka Y (2000). Effect of Sho-saiko-to extract on HGF and TGF-beta levels of intraorgans in liver-injured rats after partial hepatectomy. J Pharm Pharmacol 52:111-118.

Pérez-Tamayo R and Romero R (1958). Role of the spleen in regeneration of the liver. An experimental study. Lab Invest $7: 248-257$.

Pircher R, Lawrence DA, and Jullien P (1984). Latent betatransforming growth factor in nontransformed and Kirsten sarcoma virus-transformed normal rat kidney cells, clone 49F. Cancer Res 44:5538-5543.

Plauth M, Raible A, Gregor M, and Hartmann F (1993). Inter-organ communication between intestine and liver in vivo and in vitro. Semin Cell Biol 4:231-237.

Roberts AB (1998). Molecular and cell biology of TGF-beta. Miner Electrolyte Metab 24:111-119.

Russell WE and Coffey RJ Jr., Ouellette AJ, and Moses HL (1988). Type beta transforming growth factor reversibly inhibits the early proliferative response to partial hepatectomy in the rat. Proc Natl Acad Sci USA 85:5126-5130.

Sakai A, Taha M, Kashiwabara H, Pfeffermann R, and Kountz SL (1977). On the origin of the regeneration factor. Surg Gynecol Obstet 145:889-894.

Schrum LW, Bird MA, Salcher O, Burchardt ER, Grisham JW, Brenner DA, Rippe RA, and Behrns KE (2001). Autocrine expression of activated transforming growth factor-beta(1) induces apoptosis in normal rat liver. Am J Physiol 280: G139-G148.

Sen Gupta P, Chakraborty MS, and Aikat BK (1968). Influence of humoral and splenic factors in hepatic regeneration: An in vitro study. Indian J Med Res 56:1164-1173.

Starzl TE, Francavilla A, Porter KA, Benichou J, and Jones AF (1978). The effect of splanchnic viscera removal upon canine liver regeneration. Surg Gynecol Obstet 147:193-207.

Suzuki K, Katoh R, and Kawaoi A (1992). Immunohistochemical demonstration of proliferating cell nuclear antigen (PCNA) in formalin-fixed, paraffin-embedded sections from rat and human tissues. Acta Histochem Cytochem 25:13-21.

Uyama N, Shimahara Y, Kawada N, Seki S, Okuyama H, limuro $Y$, and Yamaoka Y (2002). Regulation of cultured rat hepatocyte proliferation by stellate cells. J Hepatol 36:590-599.

Wakefield LM, Letterio JJ, Chen T, Danielpour D, Allison RS, Pai LH, Denicoff AM, Noone MH, Cowan KH, O'Shaughnessy JA, and Sporn MB (1995). Transforming growth factor-beta1 circulates in normal human plasma and is unchanged in advanced metastatic breast cancer. Clin Cancer Res 1:129136.

Wakefield LM, Smith DM, Masui T, Harris CC, and Sporn MB (1987). Distribution and modulation of the cellular receptor for transforming growth factor-beta. J Cell Biol 105:965-975.

Wakefield LM, Winokur TS, Hollands RS, Christopherson K, Levinson AD, and Sporn MB (1990). Recombinant latent transforming growth factor beta 1 has a longer plasma half-life in rats than active transforming growth factor beta 1 , and a different tissue distribution. J Clin Invest 86:19761984.

Yasuda H, Mine T, Shibata H, Eto Y, Hasegawa Y, Takeuchi T, Asano S, and Kojima I (1993). Activin A: An autocrine inhibitor of initiation of DNA synthesis in rat hepatocytes. $\mathrm{J}$ Clin Invest 92:1491-1496. 